\title{
The role of behaviour in the assessment of poultry welfare
}

\author{
MARIAN STAMP DAWKINS \\ Department of Zoology, University of Oxford, South Parks Road, \\ Oxford OX1 3PS, UK
}

The problem of assessing welfare in poultry has been exacerbated by three widespread but erroneous assumptions. These are (1) that there are general indicators of welfare that apply to all situations, (2) that indicators of good welfare and those of reduced welfare are distinct from one another and (3) that any change in a welfare 'indicator' reflects a change in the welfare state of the animal. These three assumptions are challenged and replaced with a more evolutionary view of the behavioural and physiological responses of the domestic fowl to its environment. Apart from physical health, which is the cornerstone of all good welfare, the most important additional component of poultry welfare is psychological health or 'contentment', which can be most reliably accessed through the birds' own choice behaviour.

Keywords: Poultry; animal welfare; choice tests; welfare indicators

Many issues in animal welfare stem from the difficulty in giving a clear answer to one single question: how do we know when an animal's welfare has been either compromised or improved? This question arises whenever the welfare benefits of different housing systems for poultry are being discussed or whether there are or are not welfare benefits to be gained from introducing changes, such as reducing stocking density.

However, although there is general agreement that systems that lead to injury, disease, deformity and other signs of reduced physical health can be taken to mean reduced bird welfare (Broom and Johnson, 1993; Fraser, 1995), the possibility remains for many people that poor welfare may also result from such things as confinement, restriction or under-stimulation, even when no obvious veterinary symptoms are apparent. Indeed, as far as most consumers are concerned, good welfare means more than simply that the animals are not dying or that they are not suffering from a disease or that they have no serious injury and are not deformed. So, although good health is the cornerstone, the foundation, the basement and probably the ground floor of all good welfare, it is not enough. We need the second floor and the roof to complete the picture of what 
constitutes good and bad welfare. The search for reliable 'indicators' that provide the second part of this house of good welfare has therefore been the goal of much applied welfare research (Appleby and Hughes, 1997).

It is now widely recognised that no magic, single indicator of welfare exists and that several should be used in conjunction (Dawkins, 1980; Broom and Johnson, 1993; Mason and Mendl, 1993). However, we are still some way from agreeing exactly how to do this or, indeed, what to do with the various components when we have got them. Should we simply make a list and give a score to each one, concluding that one environment must be better for chickens than another because it gets a higher score? One obvious difficulty with such a procedure is that the answer will depend critically on the weighting that is given to the different components. A second is that different components may produce conflicting answers. Indeed, the more welfare indicators that are proposed, the greater is the problem in putting them all together to provide a coherent picture. There may be many components to the house but how is it to be built? This paper examines the role of behaviour in the construction of our ideas of what is good and bad for the welfare of poultry. It argues that behaviour has a particularly important role to play in welfare and that understanding this role better may in many cases enable us to make sense of and interpret other measures. However, in order to see it in this light, we have to stop thinking of indicators of welfare as an isolated pursuit of abnormalities in animals and cut off from the rest of biology. On the contrary, many of the so-called indicators of welfare can only be understood in the context of an animal's 'normal' biology because many of them either are or are derived from the animal's adaptive responses to hazards in the environment in which their ancestors evolved (Sapolsky, 1994; Nesse and Williams, 1995; Dawkins, 1998). This means both that applied biologists have a major contribution to make to biology in general and a great deal to learn from related disciplines, notably evolutionary biology and psychology.

Two separate components of an animal's welfare can be distinguished - its physical and its psychological health. Physical health is relatively easy to assess and few people, either farmers or the public at large, would argue that an animal's welfare is good if it is diseased or injured. In contrast, psychological health is less easy to assess but is assuming increasing importance in the minds of many people who want to be assured that the animals they rely on for food have had more than just the bare minimum of freedom from disease and ill health (Duncan, 1993). Psychological health implies that animals are, for most of their lives, content and free from negative emotional states such as pain, fear, frustration, cold and hunger. Although considerable confusion has arisen over how the psychological health of poultry can be assessed, much of this confusion can be dispelled by challenging three widespread assumptions about the assessment of animal welfare in general and poultry welfare in particular.

The first assumption to challenge is that there are general indicators of poultry welfare; in other words, that there are biochemical, physiological or behavioural signs that the psychological health of birds has been compromised, whatever the cause of that reduction in welfare. A moment's thought, however, will indicate that this is very unlikely. We know from our own experience that a bird that is fearful will have different physiological and behavioural symptoms from one that is experiencing stress as the result of exposure to heat. The idea of general (as opposed to source-specific) indicators of reduced welfare becomes even less likely if we start to consider why - in an evolutionary sense - birds respond in the ways that they do. 
Chickens do not have indicators of welfare for our benefit. What they do have is a suite of responses (biochemical, physiological and behavioural) to various kinds of dangers that have evolved in their jungle fowl ancestors and which, whether we like it or not, still persist today. Sometimes, in the highly artificial conditions in which chickens are now kept, these 'natural' responses turn out to be inappropriate or even lethal. For example, hysteria in birds kept in large groups can easily lead to suffocation as the birds pile on top of one another. But in the jungle or dry forest where their ancestors evolved, flapping and squawking when a predator approached closely may have been a highly beneficial way of escaping because it scared off or confused the predator. Although they have been domesticated and put into environments that are very different from the bamboo forests of their ancestors, modern breeds still carry with them an evolutionary heritage from their past based on millions of years of holding their own against the many threats that their ancestral environments posed - not getting enough to eat, falling victim to a predator, being overheated, frozen and so on. They have evolved to respond to each of these dangers in completely different ways. They do not respond to a water deficit by getting hysterical any more than they respond to the presence of a predator by drinking.

Because there are many different threats to animals in the wild and animals have been selected to respond to them in different ways, it follows that it is unlikely that there will be a single set of indicators that tell us that the animal's welfare is under threat. An animal whose welfare is threatened by a predator will have a different set of behavioural and physiological indicators from those of an animal whose welfare is threatened by dehydration. Furthermore, the way an animal responds to a ground predator may differ from its reaction to an aerial predator which may be different again from the way it responds to an aggressive conspecific.

Thus there will be no universal indicators of welfare. How the animal responds will depend on where the threat to welfare comes from. A priori we have no reason to expect that the responses will have much, if anything, in common. Animals do not have universal indicators of welfare because they do not have universal ways of responding to threats to their health and well-being. Rather than continuing to search for general indicators of welfare, it is much more fruitful to look at the more specific responses of poultry to particular sorts of danger such as predators (Jones, 1996) or overheating. We can expect these responses to be very different both physiologically and behaviourally and, however convenient it might be to be able to make generalisations of the type that an increase in $x$ or a decrease in $y$ always indicates a reduction in welfare, this should not be expected. It is more likely that the way in which birds respond will depend on where the threat to their welfare comes from. General indicators of welfare - that is, responses common to different sorts of threat - do exist but they should be demonstrated and not assumed.

The second widespread assumption to question is that there are indicators of enhanced welfare that are distinct from those of reduced welfare. A good practical example of such an assumption is the use that has been made of measurements of corticosteroids or 'stress' hormones. Because increased concentrations of corticosteroids are more often than not associated with situations that humans find undesirable, it is easy to assume that situations where corticosteroid concentrations are raised are likewise those that are bad for bird welfare. However, what is often not taken into account is that increased concentrations of corticosteroids are also associated with experiences that humans find pleasurable 
such as sex and the anticipation of food (Toates, 1995). Changes in the concentrations of corticosteroids are thus not necessarily an indication of poor welfare but rather of a preparation for action that may be either aversive or pleasurable for the animal. This should not come as a surprise. Hormonal changes occur as a natural part of the lives of animals as these are an integral part of how their 'behavioural machinery' works (Wingfield et al., 1997). Corticosteroids are part of the means animals have of mobilising stores of glucose and this is something that occurs whether the animal is preparing to run away from a predator (it is fearful) or to run after its prey. Both the animal that flees and the predator that runs after it need to mobilise stores of energy for the chase and, although both will thus show an increase in the concentration of so-called 'stress' hormones, the psychological state of each might be quite different. One is fearful, a state we might associate with reduced welfare, whereas the other is excited in anticipation of a good meal, and its welfare is probably enhanced.

The problem here is that the psychological health of the animal - that is, whether it is experiencing positive or negative emotions - is being judged purely on the basis of one autonomic measure, namely its hormonal state, which may give extremely variable results in poultry (Freeman, 1985; Barnett and Hemsworth, 1990; Rushen, 1991). Even taking many different physiological measurements in this situation will not necessarily distinguish the fearful prey from the happy predator. Both will have increased heart rates and both will have raised body temperatures because, by running fast (either away from danger or towards something desirable), both require their bodies to mobilise energy to get going as fast as possible. Thus the problem is not that we need to take into account more physiological measurements that are all under the control of the autonomic nervous system, but rather that autonomic responses (which tend to be what people mean when they talk about physiological measures of welfare) are often more indicative of general excitement or arousal than whether the animal is finding the source of that excitement aversive or pleasurable.

This point can be further illustrated by reference to what is now known about human emotions, where it has been recognised that autonomic responses such as changes in heart rate, temperature and hormone concentrations are very unreliable guides to what a person may be actually feeling (Wagner, 1989; Cacioppo et al., 1993). Oatley and Jenkins (1996) distinguished three systems underlying emotions in humans:

(1) cognitive/verbal: the verbal reports that people give on what they are feeling at any one time;

(2) autonomic: changes in temperature, heart rate and hormone concentrations that humans have in common with other species; and

(3) behavioural/expressive: the behavioural and facial expressions that people show with different emotions.

Although each of these can give a 'measure' of emotion, they do not necessarily correlate with each other. Sometimes, for example, strong subjective emotions occur with no obvious autonomic changes, such as when someone experiences a rapid switch from excitement to fear on a roller coaster. This does not mean that the change in emotional experience has no physiological basis. It simply means that it is probably the result of a subtle change in brain state rather than the obvious autonomic changes that most physiological methods detect. At other times the emotion we experience and report corresponds to several different kinds of autonomic change or one kind of autonomic change, such as heart rate, 
can be shown to accompany very different emotions (Frijda, 1986; Wagner, 1989; Cacioppo et al., 1993).

The rationale for using studies on humans in the quest for measurements of psychological health in poultry is that humans are the one species where we can gain an insight into what another organism is experiencing because we can ask them and get replies to our questions. Importantly, in this context, humans have many of the same autonomic responses as other species. It is clear from the study of human emotions that, if all we had was a knowledge of the autonomic responses that were occurring (for example, what their heart or breathing rates were and some measure of their hormone status), then we would not be able to tell whether that person was angry, fearful or just plain excited. This is not because there are no physiological measures of positive and negative emotions, but these are more probably a function of subtle changes in the central nervous system, not in the autonomic nervous system that sub-serves both the positive and the negative emotions. One day in the future, perhaps, we will have the technology to monitor the brain states of freely moving animals and be able to see which parts of the brain are active when they are having to cope with different situations. We may even be able to designate certain of these as pleasurable or aversive depending on which parts of the brain are active. At the moment, however, this is only a pipe dream. We do not yet have the technology to tell what the brain of an actively moving animal is doing and the only physiological measurements we currently have at our disposal are autonomic which, as already argued, do not enable us to distinguish reliably between different emotional states. So the second assumption - that we currently have indicators that enable us to distinguish between good and poor psychological health - must be questioned, at least with the physiological measurements that we currently have at our disposal.

The third assumption to question, although related to the first two, is distinct and has led to errors all of its own. This is that once a so-called welfare indicator has been identified, then any change in it is indicative of a change in welfare status. For example, if the blood concentration of a hormone has been identified as an indicator then birds with higher concentrations are automatically assumed to have poorer welfare. The fallacy of this inference should be apparent from what has already been stated because many of the responses (both behavioural and physiological) are part of the animal's evolved reaction to its environment and may not reflect a drop in its welfare status at all (Mendl, 1991). An analogy might be a central heating boiler programmed to keep a house warm at a pre-set temperature. If the boiler was running all the time but the house never attained the correct temperature, we would be right to assume that there was something wrong with the system. But in a normal house we should not jump to such a conclusion every time the boiler switched itself on as this is the expected and quite normal way in which boilers keep houses warm. We certainly should not conclude that a house in which the boiler came on more often was 'worse' than the house where the boiler came on only infrequently because the owner of one house might prefer a warmer environment or live in a colder area.

In the case of birds, changes in measures that have been used as indicators of welfare can occur as quite normal parts of their lives. For example, incubating hens lose some $17 \%$ of their body weights during the period when they are sitting on eggs (Sherry et al., 1980) as their incubation duties take priority over feeding and drinking for themselves. Because weight loss is often taken to be a sign of reduced welfare, it would be easy to presume that both the physical and 
psychological health of the hens drops during this period. However, even if the hens are provided with food at the nest, they do not eat. Natural selection has led to the evolution of hens that are anorexic and lose body weight at this time. In other words, despite not eating, they do not want to eat. They are not 'suffering' from not being able to get to food. They do not want food at that time.

Another example that illustrates how careful we have to be in assuming that any change in a welfare indicator necessarily means a loss of welfare is the way in which the strength of the immune response can vary quite naturally depending on what else is going on in the animal's life. At first sight, any reduction in the strength of the body's response to disease would seem to signify an unequivocal deterioration in the animal's health and, consequently, its welfare. However, in many species of wild animals the ability to combat disease varies with the reproductive state of the animal (Folstad and Karter, 1992). Reproductive hormones, particularly testosterone, have the natural effect of suppressing the immune system (McCruden and Stimson, 1991).

It is clear, therefore, that we should be very wary of concluding that any change in a welfare indicator necessarily means that the animal's welfare has been compromised, because many of the indicators of poor welfare are likely to be the same as natural responses and only differ from them in details of form, frequency or duration (Dawkins, 1998). Increases in corticosteroid concentrations in response to the appearance of a predator are part of the natural way in which the body prepares itself for action. Permanently raised concentrations, however, are not natural. Drinking is a natural part of the behavioural repertoire but polydipsia (drinking all the time) is not. Moving away from the flock before laying an egg is a natural behaviour in the jungle fowl but the frantic 'pacing' of a caged layer is not.

This paper does not, of course, claim that we cannot find indicators of good and poor welfare but argues that (1) we should not assume either that there are general welfare indicators or that the indicators we have available at the moment allow us to distinguish negative from positive emotions, or (2) that any change in a socalled indicator of welfare necessarily means a change in the physical or psychological health of the animal.

To avoid the pitfalls associated with these assumptions, what should we be doing? Above all, we should take an evolutionary view of the responses of poultry to various aspects of their environment. Sometimes these responses will turn out to be part of the animal's normal repertoire; sometimes they will turn out to indicate that there is something seriously wrong with the animal's physical or psychological health. Either way, there is a need for empirical investigation and the challenging of currently held assumptions. Taking an evolutionary view of animal welfare leads to the following conclusions:

(1) General signs of reduced welfare (poor physical and psychological health) are less likely to occur than specific danger-avoiding mechanisms to deal with different situations. This means that instead of pursuing a checklist of general indicators of poultry welfare applicable to all environments, we should give more weight to the way birds respond to specific situations, such as the appearance of predators or other stimuli that give rise to fear. A consequence of this would be that, in comparing, say, the welfare of birds kept in cages with those kept on free range, we would not run through the same checklist for each environment, but would attempt to break down the effects of the different stressors potentially acting on the birds in the two environments. 
(2) Situations that decrease the psychological health of birds and those that increase it (negative and positive emotions, respectively) may give rise to similar autonomic responses. Thus, using our current physiological indices of welfare, we may have great difficulty in distinguishing between them. Without further investigation we cannot even be sure that many of the autonomic changes that are used as so-called measures of welfare are not simply reflections of excitement or arousal. We certainly should not conclude that any change in these measures is indicative of reduced welfare. Although all this may sound very negative and cautionary, there is also a more positive side of taking an evolutionary view, and one where the use of behaviour comes fully into its own. Although there are difficulties in trying to assess the psychological health of chickens using the autonomic physiological measures currently available, the key to assessing the psychological health of any animal is by finding out whether it regards a particular situation as aversive - that is, something it wants to get away from - or pleasurable. In the case of humans, we can ask the question. In the case of poultry, we are obviously unable to ask them in so many words but we can find out what they like and dislike, what they attempt to escape from, and what they will work to obtain or get away from if given the opportunity (Dawkins, 1990).

(3) Choice, particularly what the animal likes and dislikes, is central to understanding the conditions for psychological health in poultry and, apart from physical health, is the most important component of welfare.

As with other aspects of their biology, poultry do not have likes and dislikes as whims or to annoy us or to make it difficult for us to keep them in the environments we wish. They have them because they are part of a wide range of mechanisms that were evolved by their ancestors in the jungle to avoid various kinds of danger. Fear, for example, is part of the bird's suite of mechanisms for avoiding danger such as predators. Its wound healing mechanisms repair damage that has already been done. Its escape responses of flying and running help it not to be wounded in the first place and its emotional state of fear helps it to avoid situations where escape mechanisms are necessary. Even aggression, which may cause problems in intensive husbandry systems, has its place in the natural social and territorial behaviour of wild birds. In fact, the evolution of animal life can be seen as the evolution of better and better ways of anticipating danger and so taking avoiding action. Thus, even a preference for the dense cover of vegetation or the company of other members of the same species can be seen as part of the predator avoidance adaptation because individuals that have such preferences will be less likely to be spotted by a predator if they keep hidden and will feel safer in the company of others if a predator does appear. Psychological health - for example, being more contented in a group than singly, being 'happier' with plenty of cover - is thus as much part of the survival mechanisms of wild jungle fowl as their ability to fly or their capacity to heal after injury, even though the absence of cover or companions may not immediately lead to death. The fact that, in nature, they make death significantly more likely in the long run has led to the evolution of emotions that make the animal take some pre-emptive action. Deviations from 'contentment' in the form of fear, frustration, pain and hunger, which then lead the animal to rectify a potentially damaging situation before it becomes lethal, serve an important function in wild animals and, annoying though it may be for us, their domesticated descendants still have many of them. 
Although different negative emotional states have, as already stated, different manifestations, what they all have in common is that the animal finds them aversive and, in various ways, will attempt to get out of them if at all possible and if given the opportunity. An important aspect of determining the state of an animal's psychological health is therefore to find out whether the animal regards itself in a situation that it finds aversive and from which it is trying to escape; or is in a situation where something vital is missing and to which it would like to gain access; or is in a situation which leaves it reasonably content and therefore not strongly motivated to do anything in particular.

There are now many different established ways of obtaining such information from simple choice tests involving two alternatives to more complex tasks in which the animal has to 'work' to get what it wants (Fraser and Matthews, 1997). All use the behaviour of the animal in one way or another but, instead of observing and analysing the frequencies of certain behaviours such as sitting, feeding and walking, which may be difficult to interpret in welfare terms, these should focus on behaviours that are directly aimed at giving the 'animal's point of view of what it likes or dislikes.

Many of these methods can also be used to measure not just simply whether a chicken likes or dislikes something, but the strength of its motivation to get away from or gain access to it (Dawkins, 1990). For example, doors giving access to commodities such as food or nest boxes can be weighted to see whether the animal will push the door, even when it is very heavy, to get what it wants (Duncan and Hughes, 1988; Petherick and Rutter, 1990). This is an important piece of information to have when using an animal's likes or dislikes to assess its welfare status, because 'suffering' implies not something mildly unpleasant but a state in which the animal has severe or prolonged negative emotions. We need to know not merely whether the animal will choose to go away from something, but will it do anything to escape? Will being in a particular environment act as a negative reinforcer and lead the animal to learn a completely arbitrary response to get itself out of it?

In conclusion, although this discussion has challenged some of the assumptions commonly used in assessing poultry welfare, it has also shown that there is a positive way forward. The search for general indicators of welfare should be replaced by concentrating on elucidating the symptoms of physical and psychological ill health that are specific to particular situations. The problems associated with the lack of a clear separation between measures of positive and negative welfare can be tackled by looking at things from the animals' point of view and discovering not only what they like and dislike but also what costs they are prepared to pay to avoid or gain access to different environments. Taking an evolutionary approach can sometimes help in interpreting the behavioural and physiological responses of poultry, even those that cause us inconvenience or loss of production, because these often have their roots in once appropriate responses of their wild ancestors. This evolutionary heritage has also left birds with strong likes and dislikes as well as mechanisms for making choices that were once essential to their survival in the wild. Despite the fact that commercial housing delivers a very different environment from the one in which the jungle fowl ancestors of our domestic breeds once lived, their welfare still depends on their being not just physically healthy but psychologically healthy or reasonably 'content' as well. The birds' own choices are thus the top floor and roof of the house that constitutes good welfare. 


\section{References}

APPLEBY, M.C. and HUGHES, B.O. (1997) Animal Welfare, CAB International, Wallingford

BARNETT, J.L. and HEMSWORTH, P.H. (1990) The validity of physiological and behavioural measures of animal welfare. Applied Animal Behaviour Science 25: 177-187

BROOM, D.M. and JOHNSON, K.G. (1993) Stress and Animal Welfare, Chapman \& Hall, London

CACIOPPO, J.T., KLEIN, D.J., BERNTSON, G.C. and HATFIELD, E. (1993) The psychophysiology of emotion. In: Handbook of Emotions (Lewis, M. and Hatfield, J.M., Eds), Guilford, New York, pp. 119-142

DAWKINS, M.S. (1980) Animal Suffering: The Science of Animal Welfare, Chapman \& Hall, London

DAWKINS, M.S. (1990) From an animal's point of view: motivation, fitness and animal welfare. Behavioral and Brain Sciences 13: 1-61

DAWKINS, M.S. (1998) Evolution and animal welfare. Quarterly Review of Biology 73: 305-328

DUNCAN, 1.J.H. (1993) Welfare is to do with what animals feel. Journal of Agricultural and Environmental Ethics 6(Suppl 2): 8-14

DUNCAN, I.J.H. and HUGHES, B.O. (1988) Can the welfare of poultry be measured? In: Science and The Poultry Industry (Hardcastle, J., Ed.), AFRC, Swindon, pp. 24-25

FOLSTAD, I. and KARTER, A.J. (1992) Parasites, bright males, and the immunocompetence handicap. The American Naturalist 139: 603-622

FRASER, D. (1995) Science, values and animal welfare: exploring the 'inextricable connection'. Animal Welfare 4: 103-117

FRASER, D. and MATTHEWS, L.R. (1997) Preference and motivational testing. In: Animal Welfare (Appleby, M.C. and Hughes, B.O., Eds), CAB International, Wallingford, pp. 159-173

FREEMAN, B.M. (1985) Stress and the domestic fowl: physiological fact or fantasy? World's Poultry Science Journal 41: 45-51

FRIJDA, N.H. (1986) The Emotions, Cambridge University Press, Cambridge

JONES, R.B. (1996) Fear and adaptability in poultry: insights, implications and imperatives. World's Poultry Science Journal 52: 131-174

MASON, G. and MENDL, M. (1993) Why is there no simple way of measuring animal welfare? Animal Welfare 2: 301-320

MCCRUDEN, A.B. and STIMSON, W.H. (1991) Sex hormones and immune function. In: Psychoneuroimmunology (Ader, R., Felten, D.L. and Cohen, N., Eds), 2nd edition, Academic Press, New York, pp. 275-294

MENDL, M. (1991) Some problems with the concept of a cut-off point for determining whenan animal's welfare is at risk. Applied Animal Behaviour Science 31: 139-146

NESSE, R. and WILLIAMS, G.C. (1995) Evolution and Healing. The New Science of Darwinian Medicine, Weidenfeld and Nicolson, London

OATLEY, K. and JENKINS, J.M. (1996) Understanding Emotions, Blackwells, Oxford

PETHERICK, J.C. and RUTTER, S.M. (1990) Quantifying motivation using a computer-controlled push door. Applied Animal Behaviour Science 27: 159-167

RUSHEN, J. (1991) Problems associated with the interpretation of physiological data in the assessment of animal welfare. Applied Animal Behaviour Science 28: 381-386

SAPOLSKY, R.M. (1994) Why Zebras Don't Get Ulcers: A Guide to Stress and Stress-Related Diseases, W.H. Freeman, New York

SHERRY, D.F., MROSOVSKY, N. and HOGAN, J.A. (1980) Weight loss and anorexia during incubation in birds. Journal of Comparative and Physiological Psychology 94: 89-98

TOATES, F. (1995) Stress: Conceptual and Biological Aspects, John Wiley, New York

WAGNER, H. (1989) The peripheral physiology and differentiation of emotions. In: Handbook of Social Psychophysiology (Wagner, H. and Mainstead, A., Eds), John Wiley, New York, pp. 78-98

WINGFIELD, J.C., HUNT, K., BREUNER, C., DUNLAP, K., FOWLER, G.S., FREED, L. and LEPSON, J. (1997) Environmental stress, field endocrinology and conservation biology. In: Behavioral Approaches to Conservation in the Wild (Clemmons, J.R. and Buchholz, R., Eds), Cambridge University Press, Cambridge, pp. 95-131 